\title{
Vulnerabilidad y deseo. Las superficies de La Casa de la Fuerza (Angélica Liddell, 2009)*
}

\author{
Edwin Culp** \\ Sara Barragán del Rey***
}

\section{Resumen}

En el contexto actual de vulneración de los cuerpos de las mujeres en América Latina, analizamos las estrategias propuestas por Angélica Liddell en su obra La casa de la fuerza (2009). En un tránsito que va desde sus experiencias personales hasta los asesinatos de mujeres en Ciudad Juárez, México —como sitio de origen y frontera de esa violencia-, Liddell conforma una resistencia que parte de las superficies y lo superficial de las anécdotas, diálogos, noticias, cuerpos e imágenes que componen la pieza. Contraponemos el análisis estético con las nociones de superficie y deseo de G. Deleuze, C. Colebrook y E. Grosz.

Palabras clave: Superficie, Vulnerabilidad, Deseo, Feminicidio, Teatro.

* Recibido el 13 diciembre 2019, aceptado el 28 agosto 2020.

** Profesor e investigador del Departamento de Comunicación de la Universidad Iberoamericana - Ciudad de México, México. edwin.culp@ibero.mx / https://orcid.org/0000-0002-6601-6705

*** Maestría en Comunicación, Universidad Iberoamericana - Ciudad de México, México. sarabarragan@gmail.com / https://orcid.org/0000-0003-3184$\underline{6079}$ 
Vulnerability and Desire. The surfaces of The House of Strength (Angelica Liddell, 2009)

\section{Abstract}

In the current context of women's bodies being vulnerated in Latin America, we analize the strategies proposed by Angelica Liddell in her work The House of Strength (2009). Through a transit that goes from her personal experiences to the murders of women in Ciudad Juárez, Mexico - taken as a site of origin and limit of that violence-, Liddell shapes a resistance based on the surfaces and the superficial quality of anecdotes, dialogues, news, bodies and images that are part of the work. We confront the aesthetic analysis with the concepts of surface and desire in G. Deleuze, C. Colebrook and E. Grosz.

Keywords: Surface, Vulnerability, Desire, Femicide, Theater. 


\section{1. "No hay cerro, ni selva, ni desierto, que nos libre del daño que los otros preparan para nosotros"}

Vivimos tiempos de indignación. Mientras realizamos esta investigación y la correspondiente escritura del manuscrito, la vulneración de los cuerpos de las mujeres a través de sistemas de dominación ha alcanzado niveles inusitados e indignantes. Por toda América Latina se han alzado diferentes voces exigiendo acabar con los abusos y, sobre todo, las muertes. Aunque hoy parecerían quedar lejanos, los asesinatos de mujeres que impunemente tuvieron lugar desde los años noventa en la fronteriza Ciudad Juárez de México constituyen un sitio de origen y a la vez límite del horror de una violencia que es parte fundamental de los procesos de neoliberalización en el continente. Ciudad fronteriza, de maquilas y fábricas donde trabajan mujeres en condiciones laborales y de vida precarias provenientes de las regiones más empobrecidas de México. A un lado, la apertura de los mercados y la libre circulación del capital, al otro, la precarización laboral, social y de las condiciones de vida —en la que resuena la exclusión colonial. Estos procesos han traído a Latinoamérica un régimen de exclusión de la vida y de las resistencias que ésta ofrece liderado por la violencia contra las mujeres y su invariable impunidad.

Esa violencia escapa constantemente a la posibilidad de una crítica desde el objeto artístico, que sea capaz de no hacer aún mayor apología de la víctima y la violencia. La obra de Angélica Liddell (Figueres, 1966) se sitúa en ese vilo, es un teatro en primera persona en el que la dramaturga, directora y actriz, se presenta como tomando como punto de partida sus experiencias personales y privadas que luego conducen a reflexiones y críticas al ejercicio del poder. Ni ella ni su trabajo han sido ajenos a estos tiempos. En La letra escarlata (2019, inspirada en la obra de Nathaniel Hawthorne), arremete contra el puritanismo y la moral que acaban por echar fuera al deseo.

Planteamos volver a La casa de la fuerza (2009), una obra de Liddell anterior a la serie de indignaciones actuales, que se 
produjo en el contexto de la Guerra contra el narco en México, y que desató como nunca la violencia en el país. La obra permite desentramar mecanismos de crítica que luego serán elaborados de maneras más complejas en su trabajo posterior. Liddell plantea seguir una estrategia que se distancia de aproximaciones esencialistas para volver a la víctima, en su lugar, propone dar cuenta de las superficies donde se produce la exclusión, el insulto o la lesión. Insistiendo en ellas, en sus imágenes, encuentra la resistencia y la fricción que esas mismas superficies de daño acaban generando. Pues en la superficie de la piel se producen los actos de violencia más desgarradores, pero también en la superficie de las emociones, en la superficie de las palabras. Y, así, la obra va construyendo por contigüidad una serie de retablos en los que lo que se acumula es la resistencia de la vida ante los embates de la fuerza. Una apuesta que permite suspender la exclusión en el límite entre lo que queda dentro y lo que no. Más que dar voz al que no la tiene, Liddell extiende al máximo el discurso del opresor al punto en que su extensión lo deja virtualmente sin fondo, convertido en pura superficie que linda con la vida -igualmente extendida - que pretendía echar fuera.

2. "Y fue así como me entregué por completo a la superficie. me entregué por completo al mundo de la fuerza"

Toda representación de la violencia - $y$, más aún, de la violencia extrema - conlleva una afrenta a la representación. Por una parte, si esta busca erigirse como sustituto de aquella violencia, capaz de condensarla en un signo, corre el riesgo de reducir y clausurar su experiencia, de no hacer suficiente justicia a aquello a lo que refiere. Con la violencia, aquello que sustituye a lo representado tiene la exigencia de ser justo con su referente, ni excederlo ni minimizarlo. Además, la propia lógica de construcción de la representación - por ejemplo, su verosimilitud- corre el riesgo de verse sobrepasada por el hecho. Los grandes trágicos lo sabían bien: sabemos que Edipo se ha sacado los ojos por un narrador, sin ver la acción directamente sobre la escena. Por otra 
parte, si desistimos de la representación en su conjunto, apelando a una dimensión ética que la igualaría con su referente, poniendo a la presentación más genuina por encima de la falsa representación, se corre el riesgo de convertir la violencia en espectáculo de sí misma, de hacer apología de la víctima que cuenta sus experiencias y exhibe su sufrimiento sobre la escena. $Y$ narrar la violencia, dar cuenta de ella, dejarse afectar por ella $-\mathrm{y}$ quizás, desde ahí, procurar una acción- pareciera ser una de las afrentas más necesarias de un arte comprometido con su tiempo; se vuelve apremiante explorar estrategias críticas de la representación que excedan los modos de síntesis y clausura y de menosprecio del aparato representativo - que podría acabar en una estrategia ingenua.

La casa de la fuerza presenta un trabajo centrado en la violencia contra las mujeres a través de las experiencias personales de Liddell, entreveradas tanto con fragmentos de Las tres hermanas de Anton Chejov como con reflexiones y experiencias sobre la violencia en Ciudad Juárez (México). Es un espectáculo divido en tres actos con una duración de cuatro horas y media incluyendo intermedios. José Antonio Sánchez la refiere como un monumento, equiparable a 2666 de Roberto Bolaño:

\begin{abstract}
(...) La casa de la fuerza era al mismo tiempo una vindicación de la fragilidad $\mathrm{y}$, simbólicamente, de las mujeres a las que "la fuerza" torturó, violó y asesinó. Por ello el monumento construido por Angélica es paradójicamente un monumento frágil, donde, como en el de Bolaño, no cabe la perfección y mucho menos el actuar virtuoso (2015:151).
\end{abstract}

Seis actrices, tres españolas y tres mexicanas, profundizan en temas como la fragilidad, y la construcción de la subjetividad femenina a partir de mecanismos de opresión y sujeción de los afectos y del cuerpo. Y lo hacen, como señala Sánchez, en una lógica representativa que no busca clausurar su relación con el referente, sino que la evidencia: es obvio que lo que vemos es una representación $e$, incluso, la vida y experiencias de las actrices 
queda entretejida en la ficción. No se trata de un actuar virtuoso, sino lleno de rupturas, interrupciones y tiempos muertos. Y las actrices en escena no son las víctimas ejemplares de esa violencia, ni siquiera testigos privilegiados, sus cuerpos son cuerpos entrenados y dispuestos para la escena; son actrices, pero no por ello niegan su afección y condición de sujeción. Las actrices exploran distintas narrativas de sí mismas en función de otros que las interpelan, si bien ausentes de la escena. Un sólo personaje, el de Liddell, se va desdoblando en la narración de sus experiencias en torno a la ruptura y el maltrato amoroso a través de otras actrices que no son sino reflejos de ella misma, reflejos similares que, más que las similitudes, manifiestan las diferencias. La humillación e injuria que sufren las mujeres, tanto desde el machismo que se vive en España, como en los asesinatos y violaciones de niñas y mujeres en Ciudad Juárez (México), articulan el contexto de este montaje.

En un primer nivel, el conflicto del montaje es el de un mundo femenino dominado por las leyes de los cuerpos fuertes y masculinos. La pieza aborda la tragedia singular del sujeto subordinado al poder, la fragilidad, la soledad y la exposición de lo femenino. Esta sujeción del sujeto es explorada en la obra a través de la narración de lo que el otro ha dicho y hecho de ellas. Un sujeto que, como dice Judith Butler, se produce desde la sujeción del poder, desde su ser interpelado, al tiempo que deviene sujeto en la puesta en práctica de ese poder (Butler, 2001). La resistencia de los cuerpos se manifiesta a lo largo de la obra en varios momentos en los que se rompen los límites impuestos y el cuerpo se abre, literalmente, a través de las heridas del cuerpo, las producidas por el dolor, por la palabra de los otros, por la violencia y los asesinatos.

Estos temas articulan el flujo consciente, el hablar automático de la pieza: podría pensarse que todo configura a un único personaje interpretado por varias actrices, letras y melodías de canciones, textos y acciones escénicas. La pieza constantemente bordea la locura: al extender y, por tanto, adelgazar la superficie se corre el riesgo constante de rasgarla. 
Cada repetición se hace más frágil y puede quedar a expensas de la pura profundidad, ahí donde la palabra pierde todo su sentido. Esta encrucijada entre quedarse en la superficie o volcarse a la profundidad sin superficie, es la que Deleuze ve - no sin desatar una polémica en torno a ella - entre Caroll y Artaud (2005). La superficie se extiende en la violencia hacia el cuerpo, el sufrimiento como elección, la narración de sexo ofrecido gratuitamente o de insultos que evocan de otros, pero dicen ellas; Liddell propone, hacia el final de la pieza, una "madre incestuosa" que dará a luz hijos débiles, de hombres buenos y débiles para disolver la fuerza, una promesa de repetición que se vuelca a la infinita división de la fuerza hasta debilitarla.

La estrategia crítica de la pieza está en tomar las interpelaciones de los otros, de la violencia, y llevarla a la necesidad de actuar sobre esta interpelación. Desde esta vulnerabilidad Butler propone una ética de la responsabilidad que interpela desde la mirada potencial del otro:

Que otro me deshaga es una necesidad primaria, una angustia, claro está, pero también una oportunidad: la de ser interpelada, reclamada, atada a lo que no soy, pero también movilizada, exhortada a actuar, interpelarme a mí misma en otro lugar y, de este modo, abandonar el 'yo' autosuficiente considerado como una especie de posesión. Si hablamos y tratamos de dar cuenta desde ese lugar, no seremos irresponsables, o, si lo somos, con seguridad se nos perdonará (Butler, 2009:183).

Liddell aborda esta necesidad de interpelar al ser interpelada como un flujo lúcido de palabras: oraciones que van de una a otra rápidamente, sin pausas; es un texto que se repite sin ser interpretado, un texto escrito para ser dicho. La emotividad que se produce no viene desde las técnicas de interpretación de la actriz, sino como producto inevitable de la relación con sus propios recuerdos. Liddell deja poco tiempo a que se asuma lo que está diciendo antes de pasar a la siguiente idea. Las pausas ocurren en momentos extraños para lo que se dice; el texto está aprendido de 
memoria, recitado más que evocado. La voz se convierte en gritos, los gritos se calman solo para la voz vuelve a desgañitarse, se conforma un ritmo dado por la respiración más que por el significado. El entendimiento de las palabras y su sentido no se dejan de lado, aún ante las rupturas y el dolor se mantiene su pronunciación y entendimiento. El conflicto permanente entre la fuerza y la soledad permite, según la propia Liddell:

ahondar en la fragilidad, la imperfección, la debilidad y la vulnerabilidad. Lo superficial (la fuerza, el sexo, las heridas, lo público) enseguida se convirtió en una manera de revelar las convulsiones de lo espantosamente profundo. Lo superficial señalaba lo secreto (2011a)

Uno de los momentos clave en la conformación de una resistencia desde la vulnerabilidad aparece en la segunda parte de la pieza. Ante el dolor por la pérdida del amor, Liddell decide "darle por culo a la inteligencia" y entregarse "por completo a la superficie"; fortalecer a profundidad y superar el dolo yendo al gimnasio, hacer ejercicios cardiovasculares para curar el corazón. Plantea la superación de un duelo amoroso haciendo "ejercicios de nosentimientos para aniquilar el exceso de sentimientos". Ejercitar la musculatura del cuerpo - su dimensión superficialpara enterrar y olvidarse del interior es uno de los motivos recurrentes de los parámetros sociales actuales. ${ }^{1} \mathrm{Y}$ Liddell lleva este tópico a su extremo. evidenciando el dolor, la vulnerabilidad y la fragilidad en la superficie misma de las palabras, los gestos y la piel. La actriz comienza a hacer ejercicio con unas pesas que, de cuando en cuando, deja en el suelo para realizarse cortes en la piel, en sus brazos, con una cuchilla de afeitar. La sangre que

${ }^{1}$ Como ejemplo en 2017 en México, el gimnasio Sports World logró un incremento de $60 \%$ de sus ingresos con la campaña publicitaria "Gym it" que invitaba a las personas a superar sus decepciones amorosas realizando ejercicio extremo en el gimnasio. A través de imágenes altamente contrastadas y con colores saturados, pueden verse a hombres y mujeres ejercitándose mientras en texto aparecen sus pensamientos en torno al matrimonio, la distancia de la pareja o la infidelidad (López, 2019). 
brota queda impresa en un pañuelo blanco que va tiñéndose de la sangre de las heridas. La acción se repite como algo rutinario de forma rítmica y pautada.

Y como ya nadie deseaba mi cuerpo y como ya nadie me amaba,

aunque yo deseaba amar con todas mis fuerzas, me puse a darle patadas [a darle por culo] a la inteligencia. ${ }^{2}$

Hice una pelota con mi puto cerebro para reventar a patadas mi puta inteligencia.

Y fue así como me entregué por completo a la superficie.

Me entregué por completo al mundo de la fuerza.

Para compensar mi debilidad con el puto mundo de la fuerza.

Y me puse a currar cuatro horas seguidas en el gimnasio y sólo encontraba alivio en la casa de la fuerza en el ejercicio de la fuerza.

Y sólo después de dos horas empezaba a desaparecer la angustia las náuseas que me provoca el desayuno.

(...)

Y después me puse a desnudarme en el chat.

Me pintaba la boca de rojo,

me ponía unas bragas bonitas,

un sujetador bonito

y conectaba la webcam.

Ellos me ensañaban la polla.

Les decía, no me enseñes la cara, hijo de puta, no me enseñes la cara.

Enséñame sólo la polla.

Y yo no les enseñaba la cara.

Y les decía que me pidieran cosas.

Me pedían que me metiera el dedo en el culo. Y yo lo hacía.

Me pedían que me metiera el dedo en el coño. Y yo lo hacía.

\footnotetext{
${ }^{2}$ En el espectáculo dice "me puse a darle por culo a la inteligencia".
} 
Me pedían que me pellizcara los pezones.

Y yo lo hacía.

Me pedían que me masturbara.

Y yo lo hacía.

Y me corría de verdad.

Y algunos me pedían que me meara encima. Pero yo no

podía mear.

Yo, así como así, no puedo mear.

(...)

Cuando no tienes amor verdadero

cualquier gilipollez

la experimentas como un sucedáneo del amor. Es como si

te amaran

cuando no tienes amor verdadero.

Cuando un gilipollas te dice:

te comería entera, preciosa,

lo experimentas como un sucedáneo del amor.

Es como si te amaran.

Me da igual si son gordos, viejos, sucios, sucios, sucios, sucios, o feos.

Me da igual.

Si no puedo ser amada, me da igual.

Además, ya no tengo 20 años, ni un buen culito

ni unas buenas tetas.

(Liddell, 2011b:62-65)

Mientras se corta la piel, escuchamos el "Cum dederit" del Nisi Dominus de Vivaldi interpretado en chelo por Pau de Nut y al que Liddell ha rebautizado como "Me cago en la puta, estoy a punto de llorar". Las heridas en la piel van sangrando mientras dice el texto y se ejercita con pesas. Su tono de voz, el paso apresurado de una idea a la siguiente, la necesidad de decir sin detenerse en lo dicho: las palabras van conformando una superficie en la que el sentido fluye de un significado a otro. La superficie herida de la piel que busca sin éxito contactar con el dolor profundo - herirse para volver a sentir- se amplía en la 
superficialidad de las palabras que dejan de remitir a un referente. Bajo la aceptación desafectada de la imposibilidad de protegerse del daño del otro y la conciencia de su cuerpo vulnerable, el dolor que antes había sido narrado en el monólogo, se escapa por la superficie de la piel. Heridas mínimas, superficiales que no por ello dejan de resonar en una profundidad vacía. Más que rasgar la superficie para derramar lo profundo, los cortes y las heridas devienen sitios de extensión erógena donde el adentro se convierte hacia afuera y el afuera hacia dentro del cuerpo:

Estos cortes en la superficie del cuerpo crean una suerte de "paisaje" de esa superficie, es decir, le generan "regiones", "zonas", capaces de significancia erótica; hacen las veces de una cuadrícula, una distribución desigual de las intensidades, de las investiduras eróticas en el cuerpo (Grosz, 1994:36).

Estas heridas hacen de la superficie del cuerpo un diagrama, con lugares de intensidad libidinal y significación especial. Al hacerlas, Liddell activa un lugar de su propio deseo, erotiza la superficie de su cuerpo yendo del dolor interior a la fortaleza exterior. Y esta superficie del deseo entre la cuchilla y la piel genera una nueva entre la sangre y un pañuelo blanco que va tiñéndose. Después elige de nuevo una canción, esta vez pop, y nos aclara que en vez de una serán dos canciones las que escucharemos, "porque mi corazón es una puta y jodida canción pop", dice. Mientras escuchamos "Muñeca de trapo" y "Dulce locura" del grupo español La oreja de Van Gogh, Liddell continúa lacerándose el cuerpo con la cuchilla y después corre en círculos de forma repetitiva. La herida, la cuchilla rompiendo la carne, es también el testimonio del daño sufrido y de la vulnerabilidad frente a los otros.

Liddell va produciendo una contigüidad entre la expansión de la musculatura y la fuerza superficial en el gimnasio, con las heridas en la piel, con el uso de su cuerpo y la cámara para dar placer a otros. No solo la superficie de placer se ha extendido por las heridas, sino que la webcam ha generado las suyas propias: al 
sucumbir al mundo de la fuerza, Liddell no cancela su propio placer y, más aún, se deja afectar por la impresión de la cámara sobre su cuerpo, afectando y desconcertando a los otros que la desean. Al dejarse ir en el mundo de la fuerza, Liddell hace evidentes las idas y venidas de esa fuerza, la resiste desde su propia vulnerabilidad, pero no sin dejarse afectar y herir a la vez. Es un gesto arriesgado, pues suspenderse en la producción de estas superficies, entre el interior y el exterior, va haciendo imposible distinguir uno del otro: donde termina el placer y violencia del otro y donde comienza el propio. Pero es justamente con este arriesgado y precario gesto que Liddell sostiene y confronta la impresión que el sistema de exclusión haría sobre ella dejando su propia impresión sobre este mismo sistema, llevándolo al borde de su propio enloquecimiento. Y ni siquiera importa hasta qué punto lo que narra es o no verdad, lo que se va conformando es el paso de una superficie a otra por contigüidad: de la sorpresa de los hombres por su ofrecimiento, de la pantalla sobre la que se proyecta el deseo de estos, del orgasmo de Liddell $\mathrm{y}$, de nuevo, a las superficies de su piel siendo cortada mientras recordamos al hombre que la dejó según nos narró antes alternando las noticias de una intervención del ejército israelí en Gaza, que ella seguía desde su soledad en Venecia. Del desamor, a la soledad, al dolor por el sufrimiento ajeno, a la "Muerte en Venecia" de Mann, al sexo por internet, a los golpes, a las heridas: "Siempre me ha llamado la atención que el sexo escandalice más que una guerra."

La relación entre causas y efectos, dolor profundo y superficie que lo expresa, se divide y diluye en el flujo por las superficies corporales. Entre herida y cicatriz, ambos efectos de la superficie, no puede sino solo establecerse, como dice Deleuze, una relación cuasi-causal, que puede revertirse (Deleuze, 2005). Las emociones y experiencias narradas han dejado de ser individuales, pero tampoco es que sinteticen a la colectividad. La estrategia de Liddell hace que sea imposible contener el flujo consciente con un signo que pueda ser asumido por la colectividad, pero tampoco permite su clausura en una experiencia que fuese solamente suya. 
Al expandir las superficies, se montan una serie de efectos sin relación entre sí; son las contigüidades de una experiencia a otra, de una palabra a otra y, de ahí, a la herida y a la sangre las que van produciendo el flujo de significados. No se horada la superficie para dar paso a la aparentemente más genuina profundidad significante, más bien se expande para ampliar la superficie y, con ella, fricción y la capacidad de resistir. Una mayor superficie de contacto supone una superficie más endeble, pero también mayor posibilidad de resistir a las deformaciones externas, adelgazando el fondo. Las superficies de contacto - la cámara con el desnudo, la mano con el sexo, la piel con la cuchilla, la sangre con el pañuelo y luego con las canciones popse extienden para ampliar el placer, generan excitaciones. Ya no son sensaciones que producen datos sensoriales o información para el cuerpo interno, sino que las excitaciones son "fenómenos de contacto y revelan lo otro como lo convexo revela el lado cóncavo de la superficie" (Lingis, 1994). Detenerse en la superficie implica dar cuenta de aquello que estuvo en contacto con ella, las fuerzas que la imprimen y la modifican, de modo que en la superficie no existe un adentro del sujeto y un afuera del objeto, sino una relación funcional entre uno y otro. Se vuelve imposible el sexo de la mano, la pantalla del pene, la guerra del dolor, la piel del corte, el sangrado o la herida. El cuerpo entero se ha vuelto pura superficie donde se inscriben otros códigos; ha devenido un juego de fuerzas, una superficie de intensidades, el sujeto encarnado es una intersección de fuerzas y afectos (Braidotti, 1994). La superficie -insignificante, pero donde se inscribe el sentidoimpide la individuación del cuerpo, constantemente llevándolo a la división y diferencia, a pasar de interioridad a exterioridad.

La piel siempre es susceptible de ser herida, es a la vez protección y vulnerabilidad, sitio y huella de la violencia, Pero también la piel es resistencia, es superficie que se imprime, capaz también de ejercer violencia. La piel y su sentido correspondiente, el tacto, son a la vez pasivos y activos, superficie cóncava y convexa. Liddell no cae simplemente en buscar una fuerza de mayor intensidad para resistir o vencer a la fuerza que la oprime; 
más bien, deja ver el diagrama de las fuerzas, tanto las que le afectan como las que ejerce. Este despliegue diagramático da cuenta de las superficies con las que contacta, de sus modificaciones, pero también de incontables movimientos de afección y acción o flujos entre interior y exterior que se dividen continuamente. Como en el tacto, afección y acción, interior y exterior, son parejas que aparecen en la superficie, pero difícilmente pueden identificarse claramente. Podríamos precisar, incluso, que la afección en Deleuze no solo se relaciona con lo inmediato, sino que ésta se da en la superficie: una serie de afecciones se acumulan o se liberan en su recorrido. La superficie divide entre interior y exterior, entre afección y afección, pero, aunque distinguimos dos no siempre podemos identificar cuál lado es cuál. Este gesto crítico permite a Liddell evitar cualquier estabilización de significados, pues siempre son susceptibles de deslizarse a otro y otro; la superficie implica un flujo de significados y, en ellos, del deseo.

La superficie no implica necesariamente su oposición con la profundidad. Si bien en apariencia serían opuestos, es evidente que no podríamos llegar a lo profundo sin haber pasado por la superficie. Y aquí quizás reside el problema: la superficie se convierte en una barrera que hay que trascender para llegar a lo verdadero y genuino, aquello que no cae en el engaño de la primera impresión. Lo superficial se asimila con el engaño o las apariencias, con aquello que hay que trascender para llegar a lo verdaderamente relevante (Hofstadter and Sander, 2013).

Buena parte de la crítica a la representación se ha construido desde ese mismo paradigma: rasgar o desgarrar el velo de la falsedad, percibido así inicialmente por los sentidos, para dejar ver lo que éste oculta y que debemos desvelar a través del pensamiento. Situar el análisis de la representación exclusivamente desde la ruptura de la superficie lleva a desdeñar el hecho de que la superficie es la única vía de acceso a lo profundo. Y el aparente acceso a la profundidad, solo es el descubrimiento de nuevas superficies, como el cirujano que debe ir pasando por las distintas capas de piel, grasa y músculo. Solo 
habría un acceso temporal a la profundidad a través de sus rupturas o rasgaduras, llegar a ella de manera contundente implicaría destruir la superficie y perder el sentido. Extender la superficie se vuelve un gesto de resistencia, cicatrización, de intentar evitar esa pérdida del sentido. Y la superficie cuando se extiende adelgaza la profundidad, haciéndose más vulnerable. De manera efectiva, se produce en la extensión de la superficie un desfondamiento del sentido, una apertura al sinsentido (Deleuze, 2005).

Liddell deja ver la tensión que la superficie provoca para el acceso a lo profundo. La tensión de la superficie jamás sustituirá a lo profundo, pero quizás nunca llegue a la profundidad. O cuando llegue no encuentre nada. La superficie opera como el espacio de la resistencia, pero también de contención. La ruptura definitiva de la superficie debe evitarse, debe contenerse el dolor. Por eso es necesario mantenerla: para salvaguardar el significado y el sentido que se despliegan en ella. Para no permitir que el sinsentido deje de dar paso al sentido y se lo coma todo.

La representación en la superficie va más allá sus posibilidades de sustitución, síntesis e identidad para abrirse a la división y diferenciación constante. En la superficie se desmiembra su relación entre causas y efectos, entre objetos y signos que los representan, y se producen puras relaciones de efectos.

El sentido, para Deleuze, no es idéntico ni a la proposición misma ni a aquello que se denota, manifiesta o significa en la proposición. Más bien, el sentido es una superficie a lo largo de la cual la proposición entra en contacto con aquello que ésta denota, manifiesta y significa, una superficie que también acerca el ámbito de los cuerpos actuales con las Ideas virtuales (Poxon y Stivale, 2011)

Situarse en la superficie supone superar la dualidad entre ilusión y verdad de la representación, una y otra confirman el mismo plano de superficie. La superficie delimita un exterior y un interior, pasando constantemente de uno a otro: es un atravesamiento topológico que se afrenta a la noción de trascendencia (Langlois, 2014). Deleuze, dice Colebrook, plantea 
que "contra la noción de trascendencia —o la idea de que lo que se sitúa fuera del pensamiento es algún objeto estático- [él] argumentaba a favor de los mundos, los planos, las superficies o los pliegues" (Colebrook, 2002). En la superficie ubica al lenguaje, el sentido y los regímenes de signos. Las superficies constituyen la dimensión inseparable entre referente e idea. Sobre ellas se producen las afectaciones, se expresan los atributos, se dan las relaciones entre exterior $e$ interior. Pero es también una radicalización de la diferencia desde la superficie, que deja fuera a la profundidad o la elevación propias de la identificación. Pensar desde las superficies y, como señala May, no pensarlas como sucedáneas de algo externo, implica una práctica de la diferencia $y$, a la vez, la diferencia en sentido afirmativo solo puede estar ligada a superficies no trascendentales (May, 1994).

Al detenerse en la superficie y hacerla visible, no dejar que pase desapercibida, se produce una afección compartida, una vibración - "Soy un tímpano" evoca El innombrable de Beckettdada por la presencia de los cuerpos. Quizás esta sea la razón por la cual la pieza funciona en la dimensión táctil y compartida de la teatralidad, generando superficies a través del escenario y hacia el espectador. La profundidad ya no da forma a lo superficial; ésta se ha adelgazado tanto como ha sido posible para incrementar la tensión superficial y, con ella, la fricción y la resistencia. Los cuerpos se han tornado en piel o en heridas, los sentimientos en placer sexual, la fuerza en musculatura. Otro personaje beckettiano viene a la mente, Molloy quien cuenta sus pedos y el ritmo de estos para constatar que sigue con vida (Beckett, 2009). O como Lewis Carroll quien, según Deleuze, lleva lo corpóreo a lo incorpóreo en Alicia a través del espejo, al tiempo que evita la pura profundidad sin superficie de Artaud (Deleuze, 2005). La profundidad es demasiado individual (cuando es causa de un efecto en la superficie) o demasiado enloquecedora (cuando no hay más una superficie que la contenga). Al fortalecer las tensiones de la superficie, se evitan las explicaciones profundas y solo queda paso para las afecciones compartidas. Suspender la superficie del dolor y la violencia, más que indagar en sus causas psicológicas, 
jurídicas o sociales, permite compartir aquello que nos es común y también resistirla a través de la propia vulnerabilidad de la superficie. La superficie se conforma desde una impresión estética, se abre en la relación interior-exterior pero esa frontera no es impermeable o infranqueable, sino que se vuelve un espacio de negociación entre uno y otro.

\section{3. "Me cago en la puta, estoy a punto de llorar"}

Liddell estructura La casa de la fuerza en tres partes, con una fuerte carga de textos tomados de registros musicales y teatrales: canciones de mariachis y corridos norteños mexicanos, canciones pop españolas de "La oreja de Van Gogh", Vivaldi y escenas modificadas de "Las tres hermanas" de Anton Chejov. La obra comienza, en la primera parte, con el prólogo de una niña que lee un texto: "No hay cerro, ni selva, ni desierto que nos libre del daño que los otros preparan para nosotros". Al fondo se escucha El corrido de Chihuahua en la versión de Lucha Reyes. Dos actrices, Getsemaní de San Marcos y Lola Jiménez, a las que luego se une la propia Liddell, y un grupo de mariachis irán confesando y cantando una serie de experiencias de rupturas amorosas y de maltrato doméstico. Mientras hablar, evocan y recrean fragmentos de escenas violentas de películas de gánsteres (Fingers, Dirty Harry): "Para que recuerdes mi nombre el resto de tu vida, tendré que levantarte inmediatamente la tapa de los sesos". El acto termina después de varias canciones y confesiones, con las actrices haciendo flexiones de bíceps con el torso desnudo en silencio.

La segunda parte - también la más larga y donde se despliegan más ampliamente las estrategias críticas de la piezacomienza retomando una pieza corta de Liddell, "Venecia" (2009), un monólogo en el que explica un viaje que hizo a Venecia justo después de una ruptura amorosa mientras registraba lo que se veía en las noticias: la intervención israelí en Gaza del mismo año, que justificaba el uso de la fuerza de parte del ejército (Liddell, 2009). La muerte, la soledad y el dolor se convierten en algo no 
del todo inteligible, como si ella misma no pudiera o desconociera exactamente su propia condición de sujeto en el relato. Sigue la interpretación del "Cum dederit" del Nisi Dominus de Vivaldi (un veneciano): "Me cago en la puta, estoy a punto de llorar." Las descripciones de Liddell dejan ver el dolor de los otros y el propio, pero también cierto sentido cómico por la exacerbación de lo que estaba pasando, sus comentarios generan una risa un tanto nerviosa en el espectador. Sigue Deleuze, "El humor es este arte de la superficie, contra la vieja ironía, arte de las profundidades o de las alturas" (2005). En sus intervenciones con el chat y la webcam, donde se desnudaba y seguía instrucciones de otros hombres, ha dejado de lado cualquier elemento que pueda construir su individualidad ("Aquí la inteligencia no cuenta. Aquí los premios no cuentan. iY tengo todos los premios!"), lo único que cuenta es la superficie: "Aquí cuenta lo evidente", dice varias veces. La actriz juega con los ritmos, las intensidades, las pausas y la pronunciación, como si aquello que dibuja la voz fuera un texto paralelo. Su entonación es una superficie por la que el texto (a veces brutal, pero siempre desafectado) se fuga para luego regresar. El monólogo se sigue de dos canciones pop de "La oreja de Van Gogh" que Liddell canta y baila llevando el dolor a la superficie y dando un nuevo sentido a las letras. En ese vilo entre el humor y la exposición del dolor, se suspende la contingencia de la afección en la superficie que Liddell va trazando de la mano de su deseo. El conflicto queda expuesto a través de sus propias palabras: lo escandaloso no es la muerte ni el sexo, lo escandaloso es la soledad. Contra el sentimiento profundo, el vaciamiento de las sensibilidades y el enfrentamiento con la superficie. Se repite una vez más la pieza de Vivaldi, mientras Liddell le da tiramisú y cuida del músico tumbado en el piso, y su repetición cobra un nuevo sentido de la primera vez: ahora la belleza se ha continuado del dolor, la sangre, el sexo, la soledad, lo abyecto.

La segunda parte se sigue de los "Tres ejercicios de felicidad para hijos de puta". Getsemaní y Lola se unen a Angélica para construir un monólogo compartido donde las tres actrices recrean una conversación con un hombre ausente, que en momentos 
recuerda a una discusión de pareja. El texto articula un discurso que desprecia y denigra a la mujer a la que está dirigido, nombrando una serie de prohibiciones o exigencias. Nuevamente, se delinea un diagrama de fuerzas desde su multiplicidad; el texto evoca a un hombre que podrían ser muchos y que hace presente un discurso dominante de subyugación del cuerpo y las emociones. El personaje múltiple cuyas palabras repiten las actrices constata su estar vivo porque la superficie de su deseo y de sus funciones escatológicas aún funcionan:

\author{
LOLA: Te meteré el brazo por el culo. \\ Trituraré a polvos tu puto culo muerto \\ con mi brazo. \\ Así sabrás lo que es el amor. \\ Te voy a rajar el culo de aquí a Groenlandia \\ para que dejes de lloriquear como una niñata \\ y sepas de una vez lo que es el puto amor. \\ Vas a probar la felicidad de mi brazo rosa \\ todavía vivo. \\ Todavía me chupan la polla. \\ Todavía tengo ganas de mear. \\ Todavía me gustan los culos. \\ Entonces todavía vivo. \\ (Liddell, 2011b: 74-75)
}

El texto es un flujo de palabras de la búsqueda de placer de un hombre a costa del sufrimiento de ellas. Las emociones y el dolor profundos se llevan a las superficies del cuerpo y las palabras, es la voz de una fuerza que va deslizándose por los imaginarios de la violencia. Es una manera de poner en acción el poder del discurso de odio, como dice Butler, el lenguaje ofensivo, la injuria. Las actrices se convierten en el lugar de su reproducción y están sujetas al enunciado del lenguaje de odio, constituidas en la subyugación en lo que, como sostiene Butler, es la operación misma de interpelación (Butler, 2004).

Paradójicamente, la supervivencia de este discurso de odio con carácter de ley se mantiene gracias a que las actrices 
reproducen la voz que, aunque espectral e insoportable, se sigue manteniendo viva. El lenguaje de odio produce heridas, pero también otros efectos innecesarios que abren la posibilidad de resignificación, que conduce al espectador a la tercera parte de la obra. La escritura, así, acorta la distancia con el cuerpo hasta superponerse de una forma violenta, como comenta Óscar Cornago en el epílogo del libro de la obra:
Así se fue acortando la distancia entre la escritura y el cuerpo hasta superponerse de una forma violenta, hasta llegar a ser literalmente escritura sobre el cuerpo, es decir, castigo asumido de un modo social que deja caer el peso de la ley (escrita) sobre quien la transgrede. El lugar de la escritura se ha ido haciendo más inmediato, más físico y doloroso (2011:137).

Horrorizan las amenazas, las injurias y la entonación con las que se dicen porque las hemos escuchado antes, se vuelven parte de las repeticiones que pueblan la obra: son gestos que hemos vivido antes, que pueden siempre volver a repetirse; y su repetibilidad aterra. La crítica de Liddell retoma discusiones de los movimientos feministas, donde la masculinidad pareciera solo preocuparse por los asuntos en general - superficiales- sin detenerse en las condiciones particulares de algo; una crítica también al humanismo que se preocupa por los ideales dejando de lado el cuerpo:

GETSE: (...) Yo no entiendo eso de consolar.

Puedo hacer daño a quien me venga en gana.

Puedo ir a lo mío.

Y no sentirme culpable.

Porque lo importante es la humanidad.

Amar a la humanidad.

A mí sólo me importan los grandes acontecimientos.

La caída del Muro, la guerra de Iraq,

las grandes luchas, las Cruzadas,

las elecciones europeas, 
los campos de exterminio en general, los conflictos armados en general, los hospitales en general, los zoológicos en general, la democracia en general. Y por eso defiendo a la humanidad.

Pero a ti, que tienes un nombre y no tienes unas buenas tetas ni un culo bonito, por qué tengo que defenderte a ti.

Eres una más.

Y puedo joderte viva como a una más.

Tú no eres un gran acontecimiento.

Tú eres insignificante y no un gran acontecimiento.

(...) Qué coñazo con la puta soledad.

Si todos estamos solos, por qué cojones me das el coñazo con la soledad. Sólo piensas en ti misma, joder.

Sólo piensas en ti misma.

No piensas en la humanidad.

Yo hago las cosas por amor a la humanidad.

(...) Yo defiendo a las mujeres muertas, joder. Yo soy un buen tío, joder.

No soy un puto machista, joder.

Yo adoro a mi madre, joder.

Yo adoro a mi madre.

¿Y dices que te quieres morir? Bueno, pues muérete.

Me la suda.

Todas las tías igual.

Yo soy distinto al resto de los tíos, ¿̇sabes? Yo soy un tío sensible.

Pero las tías, todas son iguales.

Me la suda

(Liddell, 2011b:82-87).

El discurso que se produce es el típicamente machista, pero su paso desenfrenado de una idea a otro lo lleva a lo patético, un pathos sin acción. Vamos escuchando cómo este hombre múltiple va deslizando de un sentido a otro sus pensamientos $y$ conformando una superficie de significados contradictorios, o que 
van modificándose en las repeticiones, llegando al punto de la ridiculez. Pero este deslizamiento de las palabras no conduce al humor, sino que su superficie comienza a tocarse con una realidad igualmente exacerbada: la de las vejaciones y asesinatos de mujeres en Ciudad Juárez:

GESTSE: (...) Confórmate cojones, confórmate.

No te han violado en Ciudad Juárez. Entonces confórmate.

Para sufrir te tienen que violar o disparar, así, en plan

humanidad.

Además, una puta mejicana no sufre por amor.

No te da el coñazo con eso del amor.

La violan y punto.

Son problemas de la humanidad. Confórmate (Liddell, 2011b:87).

El cuerpo es llevado a la frontera en una doble articulación: por una parte, acercando la superficie a lo corpóreo, ahí donde el desquiciamiento de las palabras se ha actualizado en violaciones, torturas, asesinatos, por otra, el cuerpo en la frontera es también una extensión de su superficie. Liddell no renuncia por la vía de la realidad, por dura que esta sea, a la resistencia de la superficie, a la exposición de la vulnerabilidad —incluso en su dimensión más radical, la vulnerabilidad que supone ser mujer en Ciudad Juárez-, renunciar la superficie supondría ceder por completo al mundo de la fuerza, dar por perdida cualquier posibilidad de resistencia, de dotar de sentido a toda esta violencia.

Sigue la segunda parte con las actrices sacándose una muestra de sangre mientras escuchamos "Rata de dos patas" de Paquita la del Barrio. Las muestras se usan para pintarse con sangre, a la altura del corazón, las camisas blancas que se han puesto. Aprovechan para retomar algunos gestos de la pieza: los disparos que se hacían cuando hablaban de las películas de gánsters. La obra toma un ritmo muy distinto, pausadamente, sin diálogos, las actrices van moviendo unos sofás sobre los que luego se acostarán mientras hacen muñecos de un bloque enorme de 
plastilina. Se abre una dimensión temporal distinta de la superficie: no un tiempo lleno de contenido y de significación sino tiempo de espera, pausa, tiempo para perder, tiempo que es pura densidad. Y la superficie, ante mayor densidad, se permite debilitarse un poco, es más fácil atravesarla y ver lo profundo. Entonces, se dirigen por primera vez a ese hombre que es muchos, la voz es queda, agotada: "porque cuando te quedas a solas con tu fuerza eres precioso, porque cuando te quedas a solas con tu reposo eres precioso" (Liddell, 2011b).

Antes de que concluya esta parte, las actrices adoptan los roles de "Las tres hermanas" de Chejov: Irina, Masha, Olga. En el libro publicado con la dramaturgia de la obra, de hecho, los nombres de las actrices (Angélica Liddell, Lola Jiménez y Getsemaní de San Marcos), se sustituyen por los nombres de los personajes. Getsemaní, interpretando a Irina, dice: "no puedo trabajar más, no quiero trabajar más. iBasta, basta! Odio y desprecio todo lo que mandan hacer. (...) Vámonos a México. Te lo suplico. Vámonos Olga, vámonos a México". México, sustituye al Moscú de la obra de Chejov, representa esa espera o esperanza de una vida mejor.

En el tercer acto, se incorporan en la escena las actrices chihuahuenses María Morales, Perla Bonilla y Cynthia Aguirre. Las mexicanas traerán a escena el documento periodístico, a través del cual contarán en monólogos los crímenes cometidos contra mujeres en Ciudad Juárez. La obra va de las canciones de dolor y las anécdotas de relaciones fallidas, al dolor por el abandono de la pareja, a las proposiciones injuriosas ensambladas desde la voz de muchos hombres reunidos en uno y dicho por las mujeres, hasta la aberración y el horror realizados en secuestros, violaciones, vejaciones y asesinatos de mujeres en Chihuahua. $Y$ no es que se establezca una relación entre ellos, en su puesta en contigüidad de una cosa se pasa a la otra sin explicación causal: no es que el machismo o los micromachismos den paso a las muertas de Juárez, pero coexisten y conforman la misma superficie de un sistema de vulneración y muerte. Mientras van narrando pausadamente, Cynthia, Perla y María se encargarán de los 
cuidados de los cuerpos de Getse, Lola y Angélica; visiblemente afectadas van recorriendo sus experiencias con la violencia y la información que cada día permea la vida cotidiana del estado de Chihuahua en México. Se toman su tiempo, no hay urgencia por nombrar a cada una de las víctimas de los feminicidios - la palabra misma no alcanza para dar cuenta de la atrocidad de lo dicho.

El texto no renuncia a las palabras y su superficie, las descripciones de las atrocidades hacen uso de la repetición como forma de insistencia en ella, aún y cuando éstas se acercan a demasiado al horror que designan. La acumulación y el uso de la conjunción parecieran posibilitar la afectación del espectador más allá de la individualización. Sobre el caso de Paulina, una de las escenas que se cuentan este acto:

\author{
Y fue raptada \\ y fue violada \\ y fue golpeada \\ y fue arrollada por el coche donde fue violada \\ y fue asesinada \\ para finalmente dejar su cuerpo tirado en un camino de \\ tierra por la carretera Aldama.
}

Paulina escribió el número de la matrícula DEL COCHE en su brazo, tal vez presintiendo su muerte.

Pudieron haber decidido no asesinarla, sin embargo optaron por asesinarla.

Cuando el cuerpo de Paulina fue encontrado en aquella brecha por Aldama ya llevaba sobre su piel EL NÚMERO 02758.

Paulina escribió el número de la matrícula DEL COCHE en su brazo, tal vez presintiendo su muerte.

Pudieron haber decidido no asesinarla, sin embargo optaron por asesinarla (Liddell, 2011b:110-111). 
Las descripciones de los delitos cometidos contra las mujeres dichas por mujeres que vienen a exponer sus cuerpos y sus voces dejan salir la náusea y el dolor. Quedan las afecciones, los instantes acumulados.

Comienza un monólogo de María. En este, se retoma el paso de una imagen a otra, de una descripción a otra, vuelve el flujo consciente, aunque desde una actoralidad visiblemente distinta a la de Liddell: aquí las afecciones han tomado un estilo más realista. Las palabras cobran imagen y evocación más abiertamente. Esta repetición de un motivo que ya hemos visto en la obra toma una nueva dimensión: la actoralidad hace visible que estamos no delante de un testigo sino de una intérprete, no por ello su experiencia se afectaría menos. El cambio de registro en las palabras escritas para ser dichas - como las que Liddell presentaba en el monólogo del segundo acto- toman otra cadencia, su decirse nos propone una cercanía distinta, la de un proceso más cercano a la identificación. Pero aquí lo que se ha volcado a su superficie es el propio espacio escénico, la repetición nos impide la identificación: lo que vemos es otro cuerpo y otra voz tomando las estrategias del primero, y lo que aparece es su radical diferencia. Particularmente cuanto más se acerca a la interpretación de Liddell, cuanto más intenta contener la afección, cuanto más se detiene la emoción, más evidente es que estas palabras siempre podrán repetirse, nunca dejarán de dividirse de un cuerpo al otro, pasan de uno a otro en sus diferencias al infinito. La vulnerabilidad, el cuerpo expuesto y el dolor reiteran una dimensión no individual. Si la primera vez podríamos estar más cerca del testimonio, ahora estamos más cerca de la teatralidad y la actuación, pero esta repetición no remite a una profundidad de lo que está siendo actuado, sino que el acontecimiento se ha vuelto aún más divisible sobre la superficie. La actriz actualiza el testimonio - que ya había sido escrito para ser dicho por otra actriz- pero sin ligar el acontecimiento a la profundidad de las cosas, sino en su pura superficie, en la pura diferencia de la superficie. Esta actuación evidente vuelve a María no solo la actriz de sus propios acontecimientos, como dirá 
Deleuze, sino la actriz de los acontecimientos de Liddell pasados por su cuerpo:

El actor efectúa pues el acontecimiento, pero de un modo completamente diferente a como se efectúa el acontecimiento en la profundidad de las cosas. O, más bien, dobla esa efectuación cósmica, física, con otra, a su modo, singularmente superficial, tanto más neta, cortante y por ello pura, cuanto que viene a delimitar la primera, destaca de ella una línea abstracta y no conserva del acontecimiento sino el contorno o el esplendor: convertirse en el comediante de sus propios acontecimientos, contraefectuación [contra-actualización] (Deleuze, 2005:184).

Esta doble división que se efectúa en la pieza, esta repetición diferente, no solo no permite la actualización de lo dicho en términos de una emoción o una acción, sino que suspende la contra-actualización de un cuerpo al otro, volviéndose en pura acumulación de la afección, de la herida en la superficie:

Y copularé con todos mis hijos para convertirlos en hombres débiles.

Daré inicio de este modo a una estirpe de incapaces.

Ninguno de ellos ejercerá más violencia que la que se emplea para respirar.

La guerra tiene lugar para oponerse a la muerte.

Con mi incesto doy el primer paso para oponerme a la fuerza.

(...) Mis hijos y yo asombraremos al mundo con nuestro exceso.

Porque el aprendizaje no puede existir sin asombro.

Después de salir cada noche de mi cuerpo

mis hijos asombrarán al mundo de los hombres fuertes.

Con su inconmensurable bondad, con su inconmensurable anemia, con su inconmensurable pereza, haré de la insignificancia un valor. Mis hijos serán hombres buenos que no sirvan para nada. Mis hijos serán hombres buenos que no sirvan para nada. 
Mis hijos serán hombres buenos que no sirvan para nada (Liddell, 2011b: 118-120).

Al final de la obra, cuando parece que ya no queda más por decir, sale a escena un nuevo actor: el hombre más fuerte de España, Juan Carlos Heredia, fisicoculturista y campeón de Strongman en España. A pesar de su fuerza, muestra un cuerpo sumamente frágil. Un cuerpo que ha expandido su superficie muscular a través del ejercicio, y que con esa expansión se ha hecho fuerte pero extremadamente frágil. Como si entre más fuerte se es, más frágilmente uno se pudiera romper. De hecho, su presencia ha limitado la movilidad de la obra, pues Heredia requiere de condiciones especiales para su alojamiento y alimentación. Este personaje, que se interpreta a sí mismo, aparece en el escenario haciendo rodar una gran piedra redonda, luego da la vuelta a un coche usando solamente su cuerpo. El cuerpo fuerte se muestra frágil y vulnerable por el agotamiento físico hacia la soledad; el vacío de lo profundo se da la vuelta en la superficie. La obra termina con la única línea de este personaje, representante de la fuerza física masculina, que repite una frase que Liddell ha dicho varias veces antes: "Amar tanto para morir tan solos". La vulnerabilidad y la fuerza se dan la vuelta en la superficie, del exterior al interior.

\section{4. "Amar tanto para morir tan solos"}

La pregunta es si ese territorio del sufrimiento superficial, donde convergen las distintas fuerzas, donde se dibujan las heridas en la piel para alcanzar a las palabras del otro, inevitables desde nuestra condición de cuerpos vulnerables, esa superficie de lo similar y lo diferente, el desplazamiento de lo metonímico, esas formas débiles que aparecen como diálogos frenéticos - figuras sin fondo- permiten al espectador afectarse por lo que ahí está ocurriendo. Si la pieza teatral consigue, desde sus estrategias de representación, tocar la superficie del espectador y dejar una 
impresión sobre ella. No es tanto un problema de conciencia como de impresión, de vibración entre interior y exterior.

No se trata de una representación que pretenda ostentar, contener o destilar la voz de las víctimas y el dolor, pero tampoco se diluye al mostrar el dolor ajeno en escena, no se trata hacer de la vulnerabilidad una exhibición. Aquí, la representación subsiste desconectada del fondo; al suspenderse en su superficie, permite el deslizamiento no causal del sentido, fluyendo sin que ningún signo se ostente como el más genuino u original. Y esto lleva a que se supere la condición de víctima: esa etiqueta que, una vez otorgada, acaba por limitar la capacidad de actuar más allá de su padecer, pero también cancela la capacidad de desear. Liddell no permite ese trato condescendiente que anula aún más a quien ha padecido el dolor. En su pieza, las superficies - y su extensión como superficie de placer- hacen emerger el deseo más allá del dolor, el deseo de quien pudiera llamarse víctima; no un deseo pasivo de ser violentada $-y$ en esto hay que ser muy cuidadosos-, sino el que la lleva más allá de la violencia ejercida. Solo pensar en ese deseo, pensar en la víctima más allá de su condición de haber sido violentada, estremece y hace vibrar las superficies. Desde la obra, se asume dicha violencia como una impresión sobre la superficie, una vulnerabilización que pasa por el tacto y la piel, y que Liddell traduce en un incremento de la fuerza desde la superficie violentada, extiende la superficie del dolor hasta el lugar donde padecer y desear se tocan. Y entonces se invierten el interior y el exterior, la fuerza ejercida se vuelve fuerza por ejercer a lo largo de esa superficie: aquí ella puede arremeter contra el otro, pero también contra todo el proceso maquínico de producción de violencias contra las mujeres.

"Y he aquí que ahora todo sube a la superficie" (Deleuze, 2005). Llevar el deseo de la víctima a la extensión de la superficie supone subvertir la lógica de sumisión y pasividad dada por la propia victimización, esa identificación con la etiqueta de víctima que no deja nada más. Si hay una producción de deseo en la superficie, ésta tendría que ser capaz de atentar contra los modos de producción de subjetividad sin deseo, de producir una lógica 
del deseo que radicalmente destituye a la máquina de sujeción de los cuerpos y el deseo machista - aunque el adjetivo no la alcanza realmente, pues su exclusión y violencia es mayor- $e$ instituye una máquina de pura superficie de placer desde la vulnerabilidad. Es la fuerza constituida desde la superficie de la vulnerabilidad. Es ahí, en ese vértigo por la superficie desfondada en el que aparece la subversión del cuerpo.

Las marcas en el cuerpo, la desnudez, la sangre, el grito, se convierten en significantes que atraviesan la obra, ahí donde la palabra subsiste - no se renuncia a ella, aunque se guarde silencio, aunque el cansancio conforme pausas- hasta en el último resquicio de dolor. La fuerza infringe el daño en lo vulnerable y lo que surge de este contacto trastoca y subvierte los términos; al ser llevado a la superficie, el dolor se ha convertido en fuerza.

\section{Referencias bibliográficas}

BECKETT, Samuel. Three Novels. New York, Grove/Atlantic, Inc., 2009.

BRAIDOTTI, Rosi. Toward a New Nomadism: Feminist Deleuzian Tracks; or, Metaphysics and Metabolism. In: BOUNDAS, Constantin V. \& OLKOWSKI, Dorothea (ed.). Gilles Deleuze and the Theater of Philosophy: Critical Essays. New York, Routledge, 1994, pp.157-186.

BUTLER, Judith. Mecanismos psíquicos del poder: teorías sobre la sujeción. Madrid, Cátedra, 2001.

. Lenguaje, poder e identidad. Madrid, Editorial Síntesis, 2004.

. Dar cuenta de sí mismo. Violencia ética y responsabilidad. Buenos Aires, Amorrortu, 2009.

COLEBROOK, Claire. Understanding Deleuze. Crows Nest, N.S.W., Allen \& Unwin, 2002.

CORNAGO, Óscar. Anotaciones al margen. In: LIDDELL, Angélica. La casa de la fuerza. Segovia, La uÑa RoTa, 2011, pp.131-140.

DELEUZE, Gilles. Lógica del sentido. Barcelona, Paidós, 2005. 
GROSZ, Elizabeth. Volatile bodies: toward a corporeal feminism. St. Leonards, NSW, Allen \& Unwin, 1994.

HOFSTADTER, Douglas R.; SANDER, Emmanuel. Surfaces and essences: analogy as the fuel and fire of thinking. New York, Basic Books, 2013.

LANGLOIS, Christopher. Deleuze's Perspectival Theory of Modernism and the Baroque. In: GONTARSKI, S. E.; ARDOIN, Paul; MATTISON, Laci (ed.) Understanding Deleuze, understanding modernism. New York, Bloomsbury, 2014, pp.207-222.

LIDDELL, Angélica. La casa de la fuerza. Dossier. 1, Teatre Lliure, 2011a. [http://www.teatrelliure.com/webantiga/1213/documents/temp1011/la _casa_de_la_fuerza_cas.pdf. - acceso Jun 30 2019].

. La casa de la fuerza. Segovia, La uÑa RoTa, 2011b.

$\begin{array}{llll}\text { Venecia. La Porta } & \text { BCN, } 2009\end{array}$ [http://laportabcn.com/en/work/venecia - Acceso Jun 27 2019].

LINGIS, Alphonso. The Society of Dismembered Body Parts. In: BOUNDAS, Constantin V.; OLKOWSKI, Dorothea (ed.). Gilles Deleuze and the Theater of Philosophy: Critical Essays. New York, Routledge, 1994, pp.289-304.

LÓPEZ, Zyanya. La campaña que cambió a Sports World. Expansión (Mercadotecnia), Ciudad de México, 2019,

MAY, Todd. Difference and Unity in Gilles Deleuze. In: BOUNDAS, Constantin V.; OLKOWSKI, Dorothea (ed.). Gilles Deleuze and the Theater of Philosophy: Critical Essays. New York, Routledge, 1994, pp.33-50.

POXON, Judith L.; STIVALE, Charles J. Sense, series. In: STIVALE, Charles J. (ed.). Gilles Deleuze: Key Concepts. Durham, Acumen, 2011, pp.67-79.

SÁNCHEZ, José Antonio. Ética y representación. México, Paso de Gato, Universidad Iberoamericana, 2015. 